\title{
EVALUASI PENERAPAN TEKNOLOGI DIGITAL SUBSTATION DI INDONESIA
}

\author{
Achmad Syerif Habibie ${ }^{1)}$, Muhammad Ridwan²), Putu Agus Aditya Pramana ${ }^{3)}$, Brian \\ Bramantyo S.D.A. Harsono ${ }^{4)}$, Muhammad Said Al Manshury ${ }^{5)}$ \\ 1,2,3,4) PT PLN (Persero) Pusat Penelitian dan Pengembangan Ketenagalistrikan \\ ${ }^{5)}$ PT PLN (Persero) UPDL Semarang \\ Email: brian.adiputro@pln.co.id ${ }^{1)}$ \\ Asal Negara: Indonesia
}

\begin{abstract}
ABSTRAK
Perkembangan pemanfaatan teknologi informasi dalam sektor ketenagalistrikan mendorong perkembangan teknologi gardu induk konvensional ke arah digital substation. Sebagai pertimbangan sebelum diimplementasikan di PT PLN (Persero), maka dilakukan kajian literatur terkait standar, protokol komunikasi, network redundancy, time synchronization, serta kelebihan dan isu pada teknologi tersebut seperti yang disajikan pada makalah ini; selain itu, diskusi dengan pabrikan digital substation yang ada di Indonesia juga dilakukan untuk memperkaya studi literatur yang dilakukan. Teknologi digital substation mengacu pada standar IEC 61850, dapat dilengkapi dengan network redundancy berupa parallel redudancy protocol (PRP) atau high-availability seamless redudancy (HSR), serta precission time protocol (PTP) untuk kebutuhan sinkronisasi waktunya. Digital substation memiliki banyak kelebihan diantaranya, yaitu: kebutuhan copper wire yang rendah, transportasi dan space yang lebih sedikit, instalasi peralatan sekunder lebih singkat, penghematan biaya (instalasi, operasi, dan pemeliharaan), pemadaman lebih singkat, peningkatan keamanan dan utilisasi aset. Sedangkan isu yang ada pada digital substation diantaranya maturity, interoperability, reliability, time synchronisation, network configuration dan bandwith management, cyber security, mixed mode, backward compatibility, suhu dan kelembaban. Selain itu, masih terdapat permasalahan pada substation automation system (SAS) yang sudah terpasang dalam rangka menuju teknologi Digital substation, namun belum tertangani dengan baik. Maturity level dari teknologi Digital substation menjadi bahan pertimbangan dalam penerapan teknologi tersebut di sistem ketenagalistrikan.
\end{abstract}

Kata kunci: Digital substation, communication protocol, network redundancy, time synchronization.

\section{ABSTRACT}

The increase of information technology usage in power utility has driven the development of conventional substations toward digital substations. Before digital substation can be considered to be implemented in PT PLN (Persero), a literature review is conducted to evaluate the related standard, communication protocol, network redundancy, time synchronization, advantages, and issues regarding this technology as written in this paper; indepth discussion with digital substation manufacturer was also conducted to enrich the literature review process. Digital substation technology used IEC 61850 as a reference and equipped with parallel redundancy protocol $(P R P)$ or high-availability seamless redundancy (HSR) for redundancy protocol and precision time protocol $(P T P)$ for time synchronization. The digital substation has many advantages compared to conventional one, e.g., low copper wire requirements, less transportation and space, shorter secondary equipment installations, cost savings (installation, operation, and maintenance), shorter blackouts, increased safety, and asset utilization. However, several issues exist in digital substation such as maturity, inter-operability, reliability, time synchronization, network configuration, and bandwidth management, cybersecurity, mixed-mode, backward compatibility, temperature, and humidity. In addition, there are still several problems with the installed substation automation system (SAS) intended for digital substation technology implementation which has not been handled properly. The Maturity level of digital substation technology should be taken into consideration in the application of this technology in the electrical system.

Keywords: Digital substation, communication protocol, network redundancy, time synchronization

\section{PENDAHULUAN}

Perkembangan pemanfaatan teknologi informasi dalam sektor ketenagalistrikan mendorong adanya perkembangan teknologi, contohnya seperti remote controling dan monitoring untuk sistem microgrid yang ada di pulau terluar (Tofani et al. 2020) serta transisi gardu induk konvensional ke arah digital substation. Pada saat ini utility sebagai pemilik gardu induk menghadapi berbagai tantangan baik itu pada saat pembangunan, pengoperasian ataupun pemeliharaan gardu induk. Tantangan tersebut diantaranya adalah isu lingkungan seperti kebocoran minyak, limbah dan polusi air, serta gas SF6. Isu operasional seperti kesinambungan pasokan, efisiensi layanan, downtime, dan overloading. Permasalahan capital expenditure seperti footprint, 
penggantian aset, dan biaya pekerjaan sipil. Selain itu, termasuk juga biaya material dan instalasi contohnya harga copper wire, biaya wiring, biaya pengujian, dan biaya tenaga kerja untuk wiring. Isu keamanan meliputi risiko kebakaran, ledakan peralatan, electrical hazard, step voltage, serta electromagnetic compatibility. Meningkatnya permintaan pembaharuan/perbaikan gardu induk, permintaan pengerjaan proyek, instalasi peralatan, dengan biaya yang lebih murah dan waktu yang lebih cepat, permintaan peningkatan pemanfaatan aset gardu induk, serta semakin berkembangnya pemanfaatan teknologi informasi di berbagai sektor termasuk ketenagalistrikan.

Salah satu hal yang memicu berkembangnya teknologi digital substation adalah karena adanya tantangan-tantangan tersebut. Gardu induk dapat disebut digital substation ketika semua data dalam gardu induk dipertukarkan melalui jaringan ethernet sehingga dalam gardu induk tersebut tidak ada lagi wiring/pengkabelan tembaga untuk sinyal input ouput, pengukuran, serta clock. Wiring yang ada pada digital substation biasanya hanya untuk power supply saja. Sedangkan pada gardu induk konvensional masih terdapat banyak wiring/pengkabelan. Berdasarkan sejumlah referensi, poin utama dalam digital substation adalah perubahan mendasar berupa adanya process bus sehingga digital substation bergantung pada komunikasi protokol oleh international electrotechnical commission (IEC) 61850 (Hinkley \& Mistry, 2018; Kumar et al., 2021; Tryapkin et al., 2018). Desain dan peralatan gardu induk menggunakan standar IEC 61850. Interface antara switchyard dan peralatan kontrol/proteksi dilakukan melalui jaringan ethernet, kabel fiber optic, menggantikan kabel tembaga yang digunakan pada gardu induk konvensional. Tegangan, arus dan sinyal digital dikirim oleh protokol komunikasi IEC 61850 berupa sampled value dan GOOSE (Bhardwaj et al., 2014; Pruthvi et al., 2013; Szela et al., 2018; Topolsky et al., 2018, 2019; Wester et al., 2015). Current transformer (CT) dan voltage transformer (VT) konvensional atau Conventional Instrument Transformer (CIT) serta peralatan switchyard lainnya didigitalisasi menggunakan merging unit (MU) dan swithgear control unit (SCU). Data-data digital tersebut dikirimkan melalui jaringan ethernet sehingga interoperasi antar perangkat lebih mudah dengan peningkatan fleksibilitas. Non-conventional instrument transformer (NCIT), baik optik maupun elektronik, mengubah nilai analog menjadi digital dan mengirimkannya melalui protokol tertentu (Hinkley \& Mistry, 2018). Adanya rancangan PT PLN (Persero) selaku BUMN pengelola ketenagalistrikan di Indonesia untuk mengimplementasikan teknologi digital substation pada gardu induk tegangan tinggi dan ekstra tinggi konvensional serta mengingat bahwa teknologi digital substation masih tergolong baru, maka perlu dilakukan evaluasi lebih mendalam terkait teknologi tersebut dari sejumlah aspek. Pada makalah ini akan disajikan hasil evaluasi dari teknologi digital substation yang nantinya dapat digunakan dalam pengambilan keputusan maupun roadmap untuk implementasi di Indonesia.

\section{METODE}

Metode yang digunakan pada makalah ini adalah studi literatur pada sejumlah referensi yang berkaitan dengan acuan standar yang berlaku, protokol komunikasi yang digunakan, network redundancy, time synchronization, serta kelebihan dan isu dari teknologi digital substation. Diskusi dengan pabrikan digital substation yang ada di Indonesia juga dilakukan untuk memperkaya studi literatur yang dilakukan.

\section{HASIL DAN PEMBAHASAN}

\subsection{Arsitektur Digital Substation}

Arsitektur digital substation pada umumnya dibagi menjadi tiga level, yaitu station level, process level, dan bay level (Chen et al., 2021; Hinkley \& Mistry, 2018; Kumar et al., 2021). Peralatan digital substation yang masuk dalam station level meliputi gateway, server, workstation beserta software-nya. Termasuk peralatan lainnya seperti printer. Peralatan digital substation yang masuk dalam bay level meliputi intelligent electronic devices (IED) diantaranya IED bay control unit (BCU), IED Proteksi, dan IED lainnya seperti IED automatic voltage regulator (AVR), IED $\mathrm{kWh}$ meter, dll (Kumar et al., 2021). Peralatan digital substation yang masuk dalam process level meliputi MU, SCU, CIT, NCIT dan peralatan lainnya yang ada di switchyard.

Sedangkan bus pada Digital substation dibagi menjadi dua, yaitu station bus dan process bus. Station bus merupakan jaringan ethernet yang menghubungkan peralatan yang ada di station level dan di bay level. Jaringan ethernet ini dibangun dengan menggunakan ethernet switch. Data status dan pengukuran yang terdapat di IED pada bay level dikirimkan ke server dan gateway pada station level melalui ethernet dengan protokol IEC 61850 (Kumar et al., 2021). Sedangkan kontrol dikirimkan dari server atau gateway pada station level ke IED di bay level. Data akan dikirimkan dari server ke workstation dan ditampilkan di lokal human machine interface (HMI), sedangkan data dari gateway akan diteruskan ke control center menggunakan protokol IEC 60870-5-101/104 atau distributed network protocol 3 (DNP3). Pada bus ini tersambung juga GPS untuk sinkronisasi waktu.

Process bus merupakan jaringan ethernet yang menghubungkan peralatan yang ada di bay level dan di process level. Jaringan ethernet ini biasanya dibangun dengan menggunakan ethernet switch. Besaran arus dan tegangan dari NCIT/CIT diubah menjadi digital dalam bentuk sampled value (SV) oleh MU (Serebryannikov et al., 2019), sedangkan 
status peralatan switchyard lainnya, seperti circuit breaker (CB) dan disconnecting switch (DS), didigitalisasi dalam bentuk generic object-oriented substation events (GOOSE) (Xia et al., 2015) oleh SCU dan data tersebut dikirimkan dalam process bus. IED yang membutuhkan data tersebut akan mengambil data tersebut dari jaringan ethernet pada process bus. Kebutuhan bandwith dalam process bus sangat tinggi, untuk $1 \mathrm{SV}$ membutuhkan $5 \mathrm{Mbps}$. Untuk itu, backbone untuk process bus harus memiliki bandwith yang tinggi hingga 1 Gbps. Process bus ini harus memiliki kehandalan yang tinggi. Salah satu alasannya karena bus ini digunakan sebagai jalur komunikasi pengganti dari hardwired CT/PT konvensional, yang mengirimkan data-data arus dan tegangan yang dibutuhkan IED proteksi agar IED proteksi tersebut bekerja secara benar.

\subsection{Protokol Komunikasi pada Digital Substation}

Service komunikasi IEC 61850 pada digital substation meliputi client-server, GOOSE, dan SV (Serebryannikov et al., 2019; Wang et al., 2020; Xia et al., 2015). Client-server merupakan komunikasi point to point yang dipakai untuk keperluan monitoring dan control. Komunikasinya menggunakan manufacturing message specification (MMS). Client-server digunakan untuk command, reporting, log, file transfer. Standar yang digunakan adalah IEC 61850 part 7 dan 8. GOOSE merupakan multicast data real-time, yang bisa digunakan dalam banyak hal misalnya untuk interlocking. GOOSE meliputi binary data, indication, dan command. Standar yang digunakan adalah IEC 61850 part 8-1. Sampled value juga merupakan multicast data realtime, yang berisi data pengukuran dari process level. Standar yang digunakan adalah IEC 61850 part 9-2, IEC 61850 part 9-2 light edition (LE).

IEC 61850-9-2 SV merupakan komunikasi unidirectional dari MU ke bay level atau IED. Transmisi data pada SV melalui physical layer berupa fiber optic serta datalink layer berupa physical layer ethernet dengan kemampuan 100Mbit/s. Standar IEC 61850-9-2 SV sangat luas, sehingga interpretasinya masih sangat lebar. Hal ini menyebabkan kesulitan interoperability antar pabrikan (Chen et al., 2021; Hinkley \& Mistry, 2018). Untuk memfasilitasi implementasi dan memungkinkan interoperability, UCA international users group (UCAIug) membuat panduan yang mendefinisikan profil aplikasi IEC 61850-9-2, biasa disebut sebagai IEC 61850-9-2 LE. Adanya IEC 61850-9-2 LE sebagai panduan dalam implementasi dan interoperabiliy dari IEC 61850-9-2. Perbedaan antara IEC 61850-9-2 dan IEC 61850-9-2 LE dapat dilihat pada Tabel 1 .

Tabel 1.

Perbedaan IEC 61850-9-2 dan IEC 61850-9-2 LE

\begin{tabular}{|c|c|c|}
\hline Parameter & $\begin{array}{c}\text { Standar } \\
\text { IEC 6180- } \\
9-2\end{array}$ & $\begin{array}{c}\text { Panduan } \\
\text { penerapan IEC } \\
6180-9-2 \text { LE } \\
\end{array}$ \\
\hline $\begin{array}{l}\text { Dibuat } \\
\text { oleh }\end{array}$ & IEC & $\begin{array}{l}\text { UCA International } \\
\text { Users Group }\end{array}$ \\
\hline $\begin{array}{l}\text { Sampling } \\
\text { rate dari } \\
\text { analog } \\
\text { value }\end{array}$ & $\begin{array}{c}\text { free } \\
\text { parameter }\end{array}$ & $\begin{array}{c}80 \text { sample per cycle } \\
\text { untuk proteksi dan } \\
\text { metering, } \\
\text { atau } 256 \text { sample per } \\
\text { cycle untuk power } \\
\text { quality }\end{array}$ \\
\hline Isi dataset & configurable & $\begin{array}{c}4 \text { tegangan dan } 4 \\
\text { arus, yaitu } \\
\text { tegangan }: 3 \text { phase }+ \\
\text { netral beserta quality } \\
\text { arus : } 3 \text { phase }+ \\
\text { netral beserta quality }\end{array}$ \\
\hline
\end{tabular}

\subsection{Network Redundancy pada Digital Substation}

Redundancy memungkinkan adanya jalur alternatif dari sumber ke tujuan. Ada dua jenis redundancy, yaitu: active redundancy (kedua link aktif pada saat yang bersamaan) serta passive redundancy (satu link aktif, yang lain dalam mode standby). Protokol redundancy yang sering digunakan adalah rapid spanning tree protocol (RSTP), high seamless redundancy (HSR) (SanchezGarrido et al., 2020), dan parallel redundancy protocol (PRP).

RSTP merupakan pengembangan dari spanning tree protocol (STP) pada standar ANSI/IEEE 802.1D-2004. RSTP menggunakan standar IEEE 802.3w, membutuhkan kurang lebih ratusan milidetik untuk melakukan rekonfigurasi jaringan jika terjadi gangguan. STP menggunakan standar IEEE 802.1D. STP dapat mencegah loop dalam jaringan, yang dapat menyebabkan broadcast storm. STP membangun satu logical tree dalam jaringan, tanpa memperhatikan konektivitas fisik. Semua link yang tidak digunakan dalam active tree akan dinonaktifkan. Jika satu aktif link gagal, spanning tree akan mengkonfigurasi ulang secara otomatis dengan mengaktifkan link yang belum aktif. Dalam STP rekonfigurasi membutuhkan waktu beberapa detik. Sementara RSTP memiliki fast convergence kurang dari 1 detik. RSTP menggunakan standar IEEE $802.1 \mathrm{w}$ dan dapat dioperasikan dengan STP IEEE 802.1D, yaitu tanpa menerapkan fast convergence. RSTP identik dengan STP, kecuali STP mempelajari rute cadangan setelah kegagalan sedangkan RSTP mempelajari rute cadangan sebelum kegagalan.

HSR memiliki arsitektur menyerupai RSTP namun memiliki transmisi data dua arah secara simultan (Sanchez-Garrido et al., 2020). HSR menggunakan standar IEC 62439-3 Klausul 5, menggunakan topologi/arsitektur ring. HSR 
memiliki zero switchover time, jika terjadi kegagalan, dan kompatibel untuk aplikasi otomasi dan proteksi. Selanjutnya HSR memungkinkan interoperability IED yang support ethernet redundancy pada sistem IEC 61850 atau dengan kata lain dapat diaplikasikan untuk multi-pabrikan. Setiap double attached node implementing HSR (DANH) memiliki dua port. Setiap port meneruskan frame yang diterimanya dari salah satu portnya ke port yang lainnya, misal dari port A ke port B atau sebaliknya. Kecuali untuk frame yang sudah diteruskan atau yang ditujukan ke node tersebut, dirinya sendiri, atau multicast/broadcast traffic yang dibuat oleh node itu sendiri. Jadi, setiap frame akan dikirimkan melalui ring sebanyak dua kali, satu ke arah kanan, atau searah jarum, dan satu ke arah kiri, atau berlawanan arah jarum jam. Redundancy Box (RedBox) digunakan untuk menghubungkan single attached node (SAN) ke jaringan HSR.

PRP merupakan protokol redundancy yang distandarisasi pada IEC 62439-3 klausul 4. Sistem yang menggunakan PRP dapat mengatasi gangguan tunggal pada jaringan tanpa mempengaruhi transmisi data (Chen et al., 2021; Hinkley \& Mistry, 2018). PRP dapat diterapkan untuk sebagian besar aplikasi ethernet karena tidak tergantung pada protokol dan menyediakan seamless failover, zero switchover time. Karakteristik PRP diantaranya adalah menggunakan standar IEC 62439-3 klausul 4, topologi/arsitektur double star, dibatasi untuk domain broadcast layer 2. Selanjutnya Arsitektur PRP menggunakan ethernet switch standar, tidak ada persyaratan khusus, tetapi untuk peralatan pada arsitektur PRP, seperti IED, MU, dan sebagainya, harus support PRP.

Dual attached node implementing PRP (DANP), misalnya IED, dan MU, memiliki dua interface ethernet dengan MAC dan alamat IP yang sama dan bekerja di layer 2, yang berarti bahwa peralatan mendukung PTP, GOOSE dan SV. DANP terhubung ke dua jaringan ethernet yang berbeda yang bekerja secara paralel. Setiap frame ditransmisikan ke kedua jaringan melalui kedua interface ethernet DANP tersebut, keduanya aktif, dan penerima memproses frame yang datang terlebih dulu dan membuang duplikat/salinannya yang datang belakangan

PRP dapat mengawasi redundansi secara terus-menerus dalam mode "duplicate discard" (kedua LAN aktif). Memungkinkan pemasangan node dengan port tunggal ke jaringan ethernet, tanpa redundansi, atau dikenal sebagai SAN. SAN hanya dapat berkomunikasi dengan peralatan yang terhubung dalam satu jaringan ethernet dimana SAN terpasang, jika menginginkan komunikasi ke kedua jaringan ethernet, harus ditambahkan RedBox. RedBox ini berfungsi untuk mengubah perangkat non-PRP menjadi PRP. Arsitektur PRP membutuhkan dua jaringan, dua interface ethernet, dan driver khusus per node. Kondisi ini meimbulkan biaya dua kali lipat, tetapi ini adalah harga untuk full redundant system. Sehingga sistem PRP memungkinkan interoperability IED yang support ethernet redundancy pada sistem IEC 61850 atau dengan kata lain dapat diaplikasikan untuk multipabrikan. Selain itu PRP juga kompatibel dengan PTP-IEEE 1588, redundant clock profile didefinisikan, memiliki zero switchover time jika terjadi kegagalan. PRP juga kompatibel untuk aplikasi otomasi dan proteksi. PRP bersifat aplication-independent, sesuai dengan jaringan ethernet industri.

\subsection{Time Synchronization pada Digital Substation}

Time synchronization perlu dilakukan untuk semua peralatan pada digital substation, terutama untuk peralatan yang kerjanya sangat bergantung pada akurasi waktu seperti MU, differential protection, fault recorder, dan lain-lain. Time synchronization pada digital substation ini sangat penting, misalnya frame SV dari berbagai MU kemungkinan memiliki delay yang tidak sama dan IED proteksi tidak akan bekerja dengan benar kecuali frame SV tersebut waktunya sinkron. Referensi sinkronisasi waktu pada digital substation pada umumnya berbasis waktu satelit. Alasan menggunakan satelit sebagai referensi waktu karena tidak memerlukan biaya, ada di semua tempat, serta handal. Selain satelit, pilihan lain untuk singkronisasi waktu adalah Glonass, Baidou, Gallileo. Terdapat beberapa protokol yang digunakan untuk singkronisasi waktu pada digital substation yaitu network time protocol atau simple network time protocol (NTP/SNTP), inter-range instrumentation group (IRIG-B) (Bhardwaj et al., 2014), serta precision time protocol (PTP) (Hinkley \& Mistry, 2018). NTP/SNTP memiliki karakteristik yaitu menggunakan media jaringan ethernet. NTP/SNTP melakukan sinkronisasi waktu antara perangkat yang beroperasi melalui packet-switched dan variablelatency data networks.

NTP/SNTP memiliki non-deterministik delay antara server dan klien NTP/SNTP dapat melakukan integrasi komunikasi data dan sinkronisasi waktu, yang dalam prosesnya memperhitungkan round trip delay. Informasi waktu termasuk tanggal dan jam, berdasarkan coordinated universal time (UTC). NTP tidak mengenali zona waktu dan daylight savings time (DST). Zona waktu dan DST dapat ditangani oleh NTP/ SNTP server. NTP/SNTP memiliki akurasi 50-100 ms

IRIG-B merupakan format khusus yang digunakan dalam aplikasi utilitas dan industri. IRIGB merupakan pengkodean waktu menggunakan pulsa tegangan pada kawat tembaga, dimodulasi atau tidak termodulasi, dan pulsa cahaya pada fiber optik. Pulsa menunjukkan waktu dari pecahan detik dari tengah malam, tanggal dari 1 Januari, dua digit terakhir dari tahun. Tergantung pada kode ekstensi dari IRIG-B, 
pulsa juga dapat menunjukkan terjadinya DST dan time offset dari UTC. IRIG-B memiliki akurasi hingga 1-10 ms (Bhardwaj et al., 2014). Kelebihan dari IRIG-B adalah memiliki presisi tinggi, banyak digunakan, serta akurasi pada sub micro second. Namun demikian, terdapat kekurangan dari IRIG-B, yaitu jumlah perangkat terbatas, jarak dibatasi oleh drop tegangan akibat copper, redundansi sulit, membutuhkan desain wiring yang teliti dan tersendiri, serta membutuhkan dedicated network.

PTP mengacu pada standar IEEE 1588 dan IEC 61850-9-3 (Hinkley \& Mistry, 2018). Media yang digunakan adalah jaringan ethernet dengan akurasi mencapai 20-100 ns. PTP mempertimbangkan delay compensation jika terdapat support hardware sehingga memungkinkan multiple master clock dan message protocol berdasarkan jaringan ethernet. Network buffering delay dan paused frame diperhitungkan untuk menentukan waktu. Segmentasi jaringan untuk memilih jalur terbaik. Memungkinkan untuk beroperasi pada advanced network (PRP, HSR, RSTP, dll). Dalam penggunannya ethernet swicth harus support PTP. PTP memiliki delay mechanism peer-to-peer (P2P). Kelebihan dari PTP adalah menggunakan jaringan ethernet, akurasi tinggi, presisi tinggi, serta memiliki karakteristik redundancy. Kekurangan dari PTP adalah masih dalam proses pengembangan.

PTP bekerja dengan menggunakan tiga konsep, yaitu best master clock (BMC), operation mode, dan delay mechanism. BMC merupakan algoritma untuk menentukan master terbaik yang akan digunakan. BMC berjalan secara menerus untuk antisipasi perubahan jaringan. Operation mode terdiri dari dua bagian, yaitu one step mode, hanya mampu sinkronisasi/delay message saja, dan two step mode, add follow up message. Delay mechanism terdiri dari end to end (E2E) dan peer-ti-peer (P2P). E2E merupakan perhitungan delay antara clock master dan clock slave. Metode ini digunakan ketika switch ethernet tidak mendukung PTP. P2P merupakan perhitungan dilakukan antar perangkat. Ethernet switch mengukur delay antrian secara internal, dimana ethernet switch harus mendukung PTP.

Dalam PTP terdapat beberapa definisi, yaitu grandmaster clock merupakan sumber waktu untuk sinkronisasi waktu menggunakan PTP. Ordinary clock merupakan clock PTP dengan port PTP tunggal, bisa sebagai master atau slave, biasanya sebagai slave pada level perangkat terakhir. Boundary clock merupakan multiple PTP ports, satu slave dan lainnya master, yang dapat berfungsi sebagai master atau slave. Mengirimkan pulsa sinkronisasi jika master hilang. Transparent clock merupakan pengkoreksi waktu dari pesan yang melaluinya serta melakukan update interval waktu dalam PTP message (Szela et al., 2018).

IEC 61850 menerima IRIG-B, PPS dan PTP untuk ini aplikasi sinkronisasi waktu pada digital substation, tetapi hanya PTP yang dapat bekerja redundant dan dapat dipetakan dalam ethernet protokol dan seperti message IEC 61850 lainnya. PTP dipetakan pada ethernet layer 2 dan menggunakan delay mechanism $\mathrm{P} 2 \mathrm{P}$, ini berarti bahwa semua peralatan, termasuk ethernet switch, merging units, IED proteksi, bay controllers, dan sebagainya, harus mendukung PTP.

\subsection{Kelebihan dan Manfaat Digital Substation}

Beberapa kelebihan dan manfaat dari digital substation seperti kebutuhan copper wire yang lebih sedikit (Chen et al., 2021; Hinkley \& Mistry, 2018; Wester et al., 2015). Copper wire yang digunakan di ruang kontrol dan proteksi digantikan dengan fiber optic dengan jumlah yang lebih sedikit, karena status, kontrol dan pengukuran dikirimkan secara digital melalui protokol IEC 61850. Digital substation menggunakan copper wire hanya untuk power supply dan wiring jarak pendek antara peralatan primer dengan marshalling kiosk (MK).

Pengurangan kebutuhan copper wire berdampak pada kebutuhan transportasi yang lebih sedikit; jumlah dan berat fiber optic yang digunakan pada digital substation lebih sedikit dan lebih ringan dari pada copper wire pada gardu induk konvensional. Jika digital substation menggunakan NCIT, ukuran dan berat NCIT lebih kecil dan lebih ringan dari pada CIT (CT/VT konvensional). Dengan lebih sedikit transportasi, maka lebih sedikit karbon dioksida yang dihasilkan dan lebih sedikit peralatan pengangkat berat yang diperlukan. Kebutuhan space di ruang kontrol dan proteksi yang lebih kecil karena ukuran IED lebih kecil. Tidak ada komponen input output konvensional seperti untuk input CT, VT, digital input, dan digital output. Tidak ada wiring dan terminal copper wire, kecuali untuk power supply. Terintegrasinya beberapa fungsi dalam satu IED, jika diijinkan.

Selaih kebutuhan transport yang lebih sedikit, kebutuhan space di switchyard juga lebih kecil karena wiring menggunakan copper wire lebih sedikit (hanya untuk power supply dan wiring jarak pendek antara peralatan primer dengan MK, selain itu sudah menggunakan fiber optic). Jika digital substation menggunakan NCIT, ukuran NCIT lebih kecil dari pada CIT, bahkan ada NCIT yang terintegrasi dengan CB. Dengan demikian, space yang dibutuhkan menjadi lebih kecil (Chen et al., 2021; Hinkley \& Mistry, 2018).

Dengan berkurangnya penggunaan copper wire, instalasi pada gardu induk menjadi lebih ringkas dan lebih mudah (terutama untuk peralatan sekunder); jumlah panel dan wiring yang perlu diinstalasi lebih sedikit serta copper wire sebagian besar digantikan oleh fiber optic dengan jumlah yang lebih sedikit (Hinkley \& Mistry, 2018). Kondisi ini juga menghasilkan penghematan biaya instalasi atau investasi. Penghematan biaya instalasi meliputi, pondasi dan space peralatan $\mathrm{CT} / \mathrm{VT}$, pondasi dan 
space bangunan, kubikel, panel, kabel, penarikan kabel, dan duct. Penghematan biaya operasi meliputi pengoptimalan fungsi operator, diagnosa gangguan lebih cepat dan pemulihan lebih cepat. Penghematan biaya pemeliharaan berupa memonitor semua data peralatan, maka pemeliharaan periodik bisa dikurangi. Monitoring secara real time memungkinkan tindakan cepat, tepat dan efisien jika terjadi kegagalan. Fitur pengujian dan simulasi IEC 61850 memungkinkan isolasi dan pengujian fungsi proteksi dan kontrol secara cepat dan aman. Kesesuaian dengan standar memungkinkan retrofit sistem sekunder di masa depan dilakukan secara efisien.

Salah satu bentuk instalasi yang lebih ringkas adalah dengan dihilangkannya sirkuit CT dan VT di panel kontrol dan proteksi; hal tersebut dapat meningkatkan keamanan pada process bus. Process bus mengganti indikasi konvensional 110 VDC dengan fiber optic. Process bus menghilangkan koneksi elektrik antara panel kontrol dan proteksi (peralatan sekunder) dengan switchyard (peralatan primer) sehingga mengurangi risiko sengatan listrik dan resiko lainnya. NCIT tidak menggunakan minyak atau SF6 sehingga mengurangi resiko kebakaran, dan polusi lingkungan. Waktu pemadaman yang lebih pendek, khususnya pada saat retrofit dan pemeliharaan peralatan sekunder. Pengujian dari proses I/O ke proteksi, kontrol dan sistem SCADA dapat dilakukan sebelum alat dipasang di site. Pemasangan fiber optic dilakukan tanpa mematikan sistem eksisting. Pemasangan peralatan proteksi dan kontrol tidak memerlukan pengkabelan copper wire, kecuali untuk power supply, cukup memasang fiber optic ke jaringan ethernet, dan penempatan IED fleksibel, tidak tergantung wiring seperti pada gardu induk konvensional. Selain itu juga dapat meningkatkan fleksibilitas penempatan peralatan dan distribusi data. Fleksibilitas penempatan panel dan peralatan kontrol/proteksi yang baru/pengganti, tanpa tergantung pada pemasangan wiring, karena sudah berbasis jaringan. Fleksibilitas dalam pendistribusian data status, kontrol dan pengukuran, karena data tersebut dikirimkan/disharing melalui protokol IEC 61850 , sehingga peralatan yang membutuhkan data tersebut tinggal mengambil dari jaringan ethernet tanpa perlu koneksi point to point secara hardwired seperti pada gardu induk konvensional.

Dari sudut pandang komisioning, acuan standar IEC 61850 memungkinkan pengujian fungsi proteksi dan control dapat dilakukan dengan secara cepat dan aman (Chen et al., 2021). Waktu pemadaman yang lebih pendek akan meningkatkan availability sistem, ketersediaan pasokan, dan pendapatan utility. Digital substation dimungkinkan untuk mendigitalisasi semua kondisi peralatan, sehingga semua peralatan dapat di monitor secara real time (online condition monitoring). Oleh karena itu, dapat dilakukan condition-based maintenance
(CBM) dan asset management untuk memaksimalkan performance dan lifetime peralatan.

\subsection{Isu dan Permasalahan Digital Substation}

Isu pada digital substation meliputi: maturity, interoperability, reliability, time synchronization, network configuration dan bandwidth management, cyber security, mixed mode, backward compatibility, suhu dan kelembaban. Teknologi digital substation pada saat ini belum mature, hal ini bisa dilihat dari penerapan digital substation yang pernah dilakukan oleh pabrikan kebanyakan masih dalam tahap pilot project untuk beberapa bay saja. Selain itu, penerapan digital substation antar pabrikan masih berbeda-beda. Sedangkan untuk teknologi NCIT, beberapa pabrikan masih dalam proses pengembangan, sedangkan yang sudah produksi, harganya masih mahal dibandingkan CIT.

Interoperability adalah kemampuan dua atau lebih peralatan IED dari pabrikan/merk yang sama atau berbeda untuk bertukar informasi dan memanfaatkan informasi tersebut untuk melaksanakan suatu fungsi tertentu dengan benar (Bhardwaj et al., 2014; Pruthvi et al., 2013). Walaupun saat ini pabrikan-pabrikan digital substation sama-sama menggunakan protokol IEC 61850 , tetapi kenyataan di lapangan ada peralatan beda merk yang tidak bisa berkomunikasi satu sama lain menggunakan protokol IEC 61850; hal ini disebabkan karena penerapan protokol IEC 61850 antar pabrikan belum tentu sama. Selain itu, interoperability antar peralatan, sangat tergantung dari kemampuan peralatan dan kemampuan teknisi dalam mengintegrasikannya dengan peralatan lain.

Dibandingkan gardu induk konvensional, jumlah peralatan pada digital substation semakin banyak, seperti MU, SCU, ethernet switch, workstation, server, gateway dan lain-lain. Semakin banyak peralatan, maka semakin tinggi pula tingkat kegagalan secara keseluruhan. Hal ini bisa dilihat juga dari pengalaman penerapan substation automation system (SAS) dibandingkan gardu induk konvensional dengan remote terminal unit (RTU), dimana peralatan SCADA pada gardu induk konvensional lebih jarang terjadi gangguan dibandingkan dengan SAS. Hal ini karena peralatan SAS kebanyakan berbasis komputer dan elektronik. Untuk meningkatkan reliability pada digital substation, dapat dilakukan dengan melakukan redundancy, tetapi memerlukan tambahan biaya yang cukup besar.

Time synchronization menjadi isu pada digital substation (Topolsky et al., 2018, 2019) terutama pada komunikasi menggunakan SV, karena SV ini menggantikan data analog arus tegangan dari CT/PT konvensional. Adanya waktu yang tidak sikron, atau adanya delay pada frame $S V$ bisa menyebabkan IED bekerja tidak sebagaimana mestinya (malfunction) (Serebryannikov et al., 2019), terutama untuk IED proteksi differential (line differential, trafo 
differential, busbar protection), yang menggunakan algoritma membandingkan nilai arus dari beberapa sumber. Jika ada salah satu SV, atau lebih, yang waktunya tidak sinkron, maka IED proteksi tersebut akan malfunction karena membandingkan beberapa nilai arus untuk waktu yang tidak sama persis. Untuk itu, SV pada Digital substation waktunya harus sinkron dan memiliki akurasi yang sangat tinggi, serta arsitektur jaringan sinkronisasi waktu, source, redundansi perlu ditentukan secara ketat, untuk mengantisipasi hal-hal yang tidak diinginkan seperti GPS gagal/rusak.

Digital substation sangat bergantung pada bandwidth, karena semua data dikirimkan melalui jaringan ethernet tersebut (Kumar et al., 2021). Kebutuhan bandwith untuk pengiriman satu SV cukup tinggi kira-kira membutuhkan 5 Mbps. Untuk itu, bandwith harus di-manage secara baik, misalnya dengan penggunaan VLAN untuk memisahkan komunikasi data yang lewat, dan penggunaan QoS untuk membuat prioritas komunikasi data sebagai antisipasi jika jaringan overload. Konfigurasi dari jaringan ethernet dalam substation (process bus, station bus) juga sangat penting, sebagai contoh konfigurasi VLAN yang tidak benar akan menyebabkan jaringan collapse. Untuk itu. diperlukan kemampuan dalam bidang networking, tidak hanya kemampuan di bidang SCADA.

Semua bentuk data pada digital substation berbentuk digital, dan digital substation ini sudah sangat bergantung pada jaringan ethernet. Karena digital substation merupakan objek vital, maka keamanan dan kehandalannya harus terjaga. Untuk itu pada digital substation harus diterapkan cyber security secara ketat agar terhindar dari serangan baik dari dalam maupun dari luar (Kwon et al., 2019). Beberapa contoh serangan yang pernah terjadi pada sistem SCADA: Maroochy Waste Water (Australia), Davis Besse Nuclear Power Plant di Ohio, dan StuxNet Worm.

Untuk digital substation yang pada salah satu bay nya masih menggunakan CT/PT konvensional tanpa MU, maka terdapat kemungkinan terjadinya mixed-mode sehingga besaran arus tegangan masih dalam bentuk analog (bay lain yang sudah menggunakan MU besaran arus tegangan dalam bentuk digital SV). Mixed-mode juga dapat terjadi pada digital substation di mana gardu induk lawannya adalah gardu induk konvensional atau apabila terjadi ekstensi bay yang tidak seragam (bay eksisting digital, sementara bay ekstensi analog); hal tersebut berpotensi menyebabkan permasalahan pada system proteksi, contohnya: proteksi line differential maupun busbar protection. Permasalahan di proteksi differential terjadi karena perbandingan besaran arus dengan sampling waktu yang tidak sama, sehingga perlu dikaji lebih lanjut apakah ada produk yang dapat mengintegrasikan konvensional (arus tegangan dalam bentuk analog) dengan digital (arus tegangan dalam bentuk digital atau SV). Jika ada produk seperti itu, sangat penting untuk memvalidasi interoperability pola tersebut untuk menilai kinerja dan stabilitasnya. Bahkan ada pabrikan yang merekomendasikan untuk proteksi differential harus sama-sama menggunakan SV dengan MU dari merk dan tipenya sama, untuk menghindari malfunction dari proteksi differential tersebut.

Backward compatibility antara IEC 61850 edisi 1 dengan edisi 2 juga menjadi salah satu isu yang disoroti dalam digital substation. Peralatan IEC 61850 edisi 1 dapat masuk ke sistem IEC 61850 edisi 2, dengan catatan parameter di sistem IEC 61850 edisi 2 mengikuti parameter IEC 61850 edisi 1 . Sedangkan jika peralatan IEC 61850 edisi 2 masuk ke sistem IEC 61850 edisi 1 maka ada beberapa masalah yang muncul. Kasus ini mungkin terjadi pada gardu eksisting lama yang menggunakan IEC 61850 edisi 1, sedangkan bay extension yang baru menggunakan IEC 61850 edisi 2. Direkomendasikan semua peralatan menggunakan IEC 61850 dengan edisi yang sama, edisi 1 semua atau edisi 2 semua.

Isu terakhir yang terkait dengan implementasi digital substation adalah kondisi udara di Indonesia yang memiliki suhu dan kelembaban yang tinggi. Sebagian peralatan digital substation seperti MU dan NCIT (yang memiliki komponen elektronik di dalamnya) dipasang di luar ruangan, sehingga perlu divalidasi kembali kinerja dan lifetime nya mengingat peralatan-peralatan tersebut kebanyakan dibuat dan digunakan oleh negara-negara Eropa yang memiliki temperatur dan kelembapan tidak tinggi seperti di Indonesia.

Apabaila direview kembali terkait SAS yang sudah terpasang di beberapa gardu induk, terdapat sejumlah permasalahan yang mungkin terjadi, yaitu: interoperability peralatan antar pabrikan masih sering menjadi kendala, konfigurator peralatan SAS tidak tersedia atau versi tidak sesuai, dokumentasi logic/GOOSE/software sebagai pengganti as built drawing tidak ada, peralatan yang akan dipasang belum lulus uji interoperability atau versi firmware yang terpasang berbeda dengan yang telah diuji, pengetahuan tentang peralatan SAS sangat tergantung merk peralatan, jumlah teknisi lokal tidak sebanding dengan jumlah proyek SAS yang ada, serta format ICD dan tipe data antar pabrikan tidak sama.

\section{KESIMPULAN DAN SARAN}

Digital substation memiliki banyak kelebihan diantaranya, yaitu: kebutuhan copper wire yang rendah, transportasi dan space yang lebih sedikit, instalasi peralatan sekunder lebih singkat, penghematan biaya (instalasi, operasi, dan pemeliharaan), pemadaman lebih singkat, peningkatan keamanan dan utilisasi aset. Sementara itu, terdapat sejumlah isu yang ada pada digital substation meliputi: maturity, interoperability, reliability, time synchronization, network configuration dan bandwith management, cyber security, mixed mode, backward compatibility, suhu 
dan kelembaban. Maturity level dari teknologi digital substation masih rendah sehingga penerapan digital substation di dunia masih dalam tahap pilot project dan pengembangan teknologi digital substation antar pabrikan masih berbeda-beda. Maturity level dari teknologi digital substation menjadi bahan pertimbangan dalam penerapan teknologi tersebut di sistem ketenagalistrikan. Pilot project dapat digunakan untuk mempelajari teknologi digital substation sebelum diterapkan secara menyeluruh terutama untuk mengantisipasi isu/permasalahan yang mungkin timbul.

\section{DAFTAR PUSTAKA}

Tofani, K.M., Pramana, P.A.A., Harsono, B.B.S.D.A., Jintaka, D.R., Mangunkusumo, K.G.H. (2020). SCADA System Design to Optimize and Automate Microgrids Systems in Indonesia. International Conference on Technology and Policy in Energy and Electric Power (ICT-PEP)

Bhardwaj, V., Singh, M. I., Pardeshi, S., \& Arora, R. (2014). A review on various standards for Digital substation. Proceeding of the IEEE International Conference on Green Computing, Communication and Electrical Engineering, ICGCCEE 2014. https://doi.org/10.1109/ICGCCEE.2014.69223 64

Chen, L., Li, H., Charton, T., \& Zhang, R. (2021). Virtual Digital substation Test System and Interoperability Assessments.

Hinkley, K., \& Mistry, C. (2018). First Digital substation in TransGrid - Australia: a journey, business case, lessons. The Journal of Engineering, 2018(15), 1135-1139. https://doi.org/10.1049/joe.2018.0171

Kumar, S., Abu-Siada, A., Das, N., \& Islam, S. (2021). Toward a substation automation system based on iec 61850. Electronics (Switzerland), $10(3)$, $1-16$. https://doi.org/10.3390/electronics 10030310

Kwon, Y., Lee, S., King, R., Lim, J. I., \& Kim, H. K. (2019). Behavior analysis and anomaly detection for a Digital substation on cyberphysical system. Electronics (Switzerland), $8(3)$.

https://doi.org/10.3390/electronics8030326

Pruthvi, P., Bhuvaneswari, H. B., \& Sudheendran, L. (2013). Analysis of utility communication protocol IEC 61850 for substation automation systems. IET Conference Publications, $2013(648$

$\mathrm{CP})$. https://doi.org/10.1049/cp.2013.2504

Sanchez-Garrido, J., Jurado, A., Medina, L., Rodriguez, R., Ros, E., \& Diaz, J. (2020). Digital Electrical Substation Communications Based on Deterministic Time-Sensitive Networking over Ethernet. IEEE Access, 8,
93621-93634.

https://doi.org/10.1109/ACCESS.2020.299518 9

Serebryannikov, A. V., Zinovev, D. V., Kravchenko, G. A., Kalinin, A. G., Ilin, D. V., \& Ilina, L. A. (2019). Principles for reducing the phase shift between instantaneous analogue and discrete signals and the corresponding values in the sampled values (SV) stream of a Digital substation. E3S Web of Conferences, 124, 1-4. https://doi.org/10.1051/e3sconf/20191240103 5

Szela, W., Gdowik, E., Vardhan, H., \& Ramlachan, R. (2018). Deploying Digital substations: Experience with a Digital substation Pilot in North America Harsh Vardhan, R Ramlachan GE Grid Solutions , USA Wojciech Szela , Edward Gdowik. 2018 71st Annual Conference for Protective Relay Engineers (CPRE).

Topolsky, D. V., Topolskaya, I. G., \& Plaksina, Y. G. (2019). Digital Measurement System to Substation Automation Systems. Proceedings 2019 International Russian Automation Conference, RusAutoCon 2019, 1-6. https://doi.org/10.1109/RUSAUTOCON.2019 .8867713

Topolsky, D. V., Topolskaya, I. G., \& Topolsky, N. D. (2018). Development of an Intelligent Measuring System for Digital substations. 2018 International Multi-Conference on Industrial Engineering and Modern Technologies, FarEastCon 2018, 1-4. https://doi.org/10.1109/FarEastCon.2018.8602 868

Tryapkin, E., Ignatenko, I., \& Keino, M. (2018). Development of "Digital substation" technology for power supply of railways. MATEC Web of Conferences, 239. https://doi.org/10.1051/matecconf/201823901 051

Wang, S., Yang, F., Yan, X., \& Liu, T. (2020). Analysis of GOOSE message and the engineering application for GOOSE message in the intelligent substation. The Journal of Engineering, 2020(6), 207-212. https://doi.org/10.1049/joe.2018.5208

Wester, C., Engelman, N., Smith, T., Odetunde, K., Anderson, B., \& Reilly, J. (2015). The role of the SCADA RTU in today's substation. 2015 68th Annual Conference for Protective Relay Engineers, CPRE 2015, 622-628. https://doi.org/10.1109/CPRE.2015.7102199

Xia, F., Xia, Z., \& Huang, X. (2015). Summary of GOOSE substation communication. MATEC Web of Conferences, 25, 1-8. https://doi.org/10.1051/matecconf/201525010 07 